\title{
An evaluation of implementing problem-based learning scenarios in an immersive virtual world
}

\author{
Maggi Savin-Baden' ${ }^{1}$, Cathy Tombs ${ }^{1}$, Terry Poulton ${ }^{2}$, Emily Conradi ${ }^{2}$, Sheetal Kavia ${ }^{2}$, David Burden ${ }^{3}$, \\ Chris Beaumont ${ }^{4}$
}

${ }^{1}$ Learning Innovation Research Group, Coventry University, UK

${ }^{2}$ E-Learning Unit, Centre for Medical and Healthcare Education, St. George's University of London, UK

${ }^{3}$ Daden Limited, Moseley, Birmingham, UK

${ }^{4}$ Edge Hill Business School, Edge Hill University, Ormskirk, UK

Correspondence: Maggi Savin-Baden, Director, Learning Innovation, Enterprise Centre EC2.1, Coventry University Technology Park Puma Way Coventry, CV1 2TT, UK. Email: m.savinbaden@coventry.ac.uk

\begin{abstract}
Objectives: This paper will describe a project adopting a pedagogical approach that implemented and evaluated a problem-based learning project in an immersive virtual world. The project involved an iterative process of testing scenarios using student feedback to improve upon the scenarios.

Methods: The study used illuminative evaluation which is argued to take account of wider contexts than more traditional evaluation and, is primarily concerned with description and interpretation rather than measurement and prediction. The evaluation encompassed formative elements to inform the project team and summative elements to establish the worth of what was achieved.
\end{abstract}

Results: The findings in many ways were more positive than initially anticipated, but there were also a number of challenges. The themes that emerged for the data were technological challenges, pedagogical design, usability and avatar identity, collaboration and Interaction.

Conclusions: Students appreciated the value of Second Life as a collaborative environment, but also viewed such practice-based simulations as valuable for individual work. An interesting consequence of the richness and authenticity of the Second Life scenarios is the large amount of detail provided, much more than is usual in paper-based face-to face problem-based learning sessions.

Keywords: Problem-based learning, evaluation, immersive virtual worlds, pedagogy

\section{Introduction}

Most research in the early 2000s on learning in immersive worlds has been undertaken into students' experiences of the virtual learning environments (VLEs), and perspectives about what and how online learning has been implemented. ${ }^{1,2}$ Immersive virtual worlds (IVWs) are online 3D virtual worlds. Self-designed avatars (virtual people) in this world interact with each other and can learn, socialize, participate in activities, and buy and sell items with one another. Learning and teaching through this $3 \mathrm{D}$ environment offers learners and teachers the opportunity to explore the impact of issues such as embodiment, identity and spatiality in the learning process. However, this paper suggests that there is still a lack of pedagogical underpinning relating to the use of virtual worlds in higher education, for example there are currently few research papers that suggest why such worlds are being used or adopting social forms models of education which would seem a better fit than the current behaviour models that largely operate across most of the global higher education system. The paper presents the PREVIEW project (Problem-based Learning in Virtual Interactive Educational 
Worlds) that sought to combine pedagogy with technology, which has been tested in health, medicine and social care and is now currently being tested in education, physiotherapy and psychology. This article centres on the development and evaluation of the demonstrator. Further related papers were published elsewhere..$^{3-7}$ It is argued here that the current lack of pedagogical underpinning has introduced a number of difficulties, little understanding about which kinds of pedagogies best work in virtual worlds and which do not and what the impact is of using these 3D spaces on student learning and student engagement. It is suggested here that these difficulties might be overcome by using approaches that readily combine pedagogy with technology, thereby shifting from the VLEs to IVWs.

\section{Background}

Problem-based learning (PBL) was popularised in the 1980 s, partly in response to the predominantly contentdriven transmission educative model of the time. For example those leading the development of PBL in Canada and the Netherlands ${ }^{8,9}$ argued that content-driven transmission models such as lecture-based learning programmes did not help students to apply knowledge to practice. Thus an increasing number of curricula are based on a particular variant of case based learning: PBL which is an approach in which students work in teams to manage or solve a problem. ${ }^{10}$ Guided by a tutor they share their existing knowledge and understanding relevant to the scenario, agreeing on what they need to learn and how to carry it out. Medicine and Healthcare education have used this approach in the UK since the mid-1980s but there has been a shift in the last three years toward moving into online and immersive spaces. ${ }^{6,11}$ Consequently PBL arose out of a desire to give students the opportunity to apply practices and theoretical knowledge to problems or scenarios within the professional or clinical setting, crucially in interactive collaboration with colleagues, thus replicating features of the real-life context of application. It has become an increasingly influential approach in curricula in a variety of settings, across a range of subject areas. The increasing adoption of PBL and the growth in online learning each reflect the shift away from teaching as a means of transmitting information, towards supporting learning as a student-generated activity. To date PBL has been seen as a relatively stable approach to learning, delineated by particular characteristics and ways of operating. Most of the explanations of and arguments for problem-based learning, thus far, have tended to focus on (or privilege) the cognitive perspectives over the ontological position of the learner. However, facilitating this collaborative approach to participation and learning is considerably more challenging in self-directed and distance learning contexts, due to difficulties associated with effective discussion between geographically and spatially disparate learners. However, linking PBL with IVWs brings other challenges, for example ensuring students are able to access the virtual world, understating their roles within the virtual scenarios and learning how to work as a team in a $3 \mathrm{D}$ space. ${ }^{7,}{ }^{12}$ Yet there is an increasing interest in the use of immersive worlds for learning. One of the reasons for such interest appears to be a recognition that for students in workplace or competency-led courses, learning through case-based scenarios is an excellent method for acquiring sound knowledge and developing decision-making and problem solving skills.

\section{Informing literature}

It could be argued, and increasingly is, that cyberspace has resulted in a sense of multiple identities and disembodiment, or even different forms of embodiment. The sense of anonymity and the assumption that this was what was understood through one's words rather than one's bodily presence, is becoming increasingly unmasked through worlds such as Second Life (SL). However, before this is explored it is perhaps helpful to delineate current forms of PBL.

\section{Face-to-face problem-based learning}

Problem-based learning was an approach popularised by Barrows and $\mathrm{Tamblyn}^{8}$ following their research into the reasoning abilities of medical students at McMaster Medical School in Canada. This was because they found that students could learn content and skill, but when faced with a patient could not apply their knowledge in the practical situation. Barrows and Tamblyn's study and the approach adopted at McMaster marked a clear move away from problem-solving learning in which individual students answered a series of questions from information supplied by a lecturer. In this early version of problem-based learning certain key characteristics were essential. Students in small teams would explore a problem situation and through this exploration were expected to examine the gaps in their own knowledge and skills in order to decide what information they needed to acquire in order to resolve or manage the situation with which they were presented. The 'problems', also termed 'scenarios' are central to student learning in each component of the curriculum (modules/units). In practice any lectures, seminars, workshops or laboratories support the problem-based process rather than being just a mechanism for transmitting subject-based knowledge. Whether it is a module or a whole programme that is being designed, the starting point should be a set of problem scenarios that enable students to become independent inquirers and help them to see learning and knowledge as flexible entities. To date there has been little in-depth discussion about the design of problem-based curricula. Instead the discussions have tended to centre on what counts as problem-based learning, ways of implementing it and types of problem-based learning. 


\section{Problem-based learning online}

Problem-based learning online is defined here as students working in teams together online of four to six on a series of problem scenarios that combine to make up a module or unit (a 12 week teaching block) that may then form a programme. Students are expected to work collaboratively to solve or manage the problem. Students will work in realtime or asynchronously, but what is important is that they work together. Synchronous collaboration tools are important for the effective use of PBLonline because tools such as Chat, Shared Whiteboards, Video conferencing and Group browsing help to ensure collaboration within the problem-based learning team, however such synchronicity is not always possible across contents and time zones. What is also important is that students have both access to the objectives of the module and also the ability to negotiate their own learning needs in the context of the given outcomes. Facilitation occurs through the tutor whose role it is to ensure the team work effectively and whose role it is to operate within the team as someone who supports and facilitates discussion rather than directs it. The role of the tutor is also to plan real-time sessions with the PBLonline team in order to engage with the discussion and facilitate the learning.

For students the shift to new forms of learning, different from the more traditional didactic approaches they have experienced in school and further education, is often challenging. PBLonline introduces students to two new elements of learning (problem-based learning and learning in online teams) which can have an impact not only on the problem-based learning and online learning but also on other forms of learning within the curriculum. There are few curricula where problem-based learning is used as the only approach to learning ${ }^{11,13}$ and increasingly students have to manage not only the interplay of knowledge across modules but also different approaches to learning. However, there are also issues about the reasons for using PBLonline in the first place. For example, it is questionable as to whether there is value in using real-time PBLonline for students undertaking the same programme at the same university, unless it is used because of long distances between campus sites where students are using the same problem-based learning scenario. There also needs to be questions asked about whether having asynchronous teams adds something different to PBLonline. Certainly, in distance education, across time zones and campus sites, this would be useful and suit different students' lives and working practices. Yet this raises problems about how cooperative and collaborative it is possible to be, in terms of sharing learning and ideas and developing forms of learning that are genuinely dialogic in nature.

\section{Problem-based learning in immersive virtual worlds} A good deal of the recent research into learning in immersive virtual worlds centres around games and gaming and is largely underpinned by cognitive learning theories that focus on linearity, problem-solving and the importance of attaining the 'right answer' or game plan ${ }^{14,15}$. Most research to date has been undertaken into students' experiences of virtual learning environments, discussion forums and perspectives about what and how online learning has been implemented. ${ }^{16}$ Although PBLonline combines problembased and online learning, in doing so it is recognised that students learn collaboratively through web-based materials including text, simulations, videos and demonstrations. Resources such as chat rooms, message boards and environments have been purpose-built for PBL; both synchronously and asynchronously, on campus or at a distance. Practising skills within a virtual environment online offers advantages over learning through real-life practice, in particular the exposure of learners to a wide range of scenarios (more than they are likely to meet in a standard face-to-face programme) at a time and pace convenient to the learner, together with consistent feedback. For example although university virtual learning environments still continue such as (such as Blackboard), immersive platforms such as SL offer a visual experience, and a sense of 'being' in a learning space in ways that virtual learning environments do not. Even if this very visuality may not be vital for students on face to face courses, it does appear to help those on distance programmes to feel more engaged with peers and what is being learned on the course. The value of the visual nature of SL is in the ability to use it for learning in visual ways not possible in real life. For example, it is possible to build houses that replicate real life homes in which occupational therapists can evaluate whether the house is suitable for a patient to return to following a hip replacement. It is possible to create a crime scene where police students can consider how to take photographs and understand the importance of not contaminating it. For paramedic students it is possible to engage with an accident and gain feedback on their performance without the risk of someone dying through their mistakes. One example is the PREVIEW project. ${ }^{17}$ This project investigated, implemented and evaluated a user-focused approach to developing scenarios and materials, linking the emerging technologies of virtual worlds with interactive $\mathrm{PBL}$ online, to create immersive collaborative tutorials.

\section{Objectives}

This project investigated, implemented and evaluated a user-focused approach to developing scenarios and materials, linking the emerging technologies of virtual worlds with interactive $\mathrm{PBL}$ online, to create immersive collaborative tutorials. The project team, led by Coventry University and its partner St George's University of London, implemented and evaluated a user-focused approach to developing problem-based learning environments and 'good practice' materials. This was achieved by linking the emerging technologies of virtual worlds with interactive PBL online to 
create immersive, collaborative tutorials in the virtual world SL, which allows distance learners from the geographically distant institutions to meet 'in-world' and collaborate around a case (examples are provided in the Appendix 1).

This environment differs radically from the VLE in that it draws on a primarily visual set of semiotic resources with each participant having an online presence, or avatar, to aid their communication. The aims of the PREVIEW project were to:

- Deliver problem-based learning in SL

- Develop eight interactive PBL scenarios

- Evaluate the scenarios from users' perspectives alongside users

- Develop guidelines and best-practice for delivering PBL in immersive worlds

- Share open source materials and technology

- Publish findings in medical and higher education literature

A variety of problem-based learning scenarios were developed within SL for distance-learning students at the two institutions. The project was introduced to the part-time distance online MA in Health and Social Care Management at Coventry University. The project was also implemented on the second year of the three-year blended learning Paramedic Foundation Degree at St George's University of London. The PBL scenarios were categorised in two ways: information-driven scenarios, and avatar-driven scenarios. Information-driven scenarios focus on internal virtual world content, such as media technologies (video footage, images and audio) and objects within the virtual environment that provide the user with written or spoken information. The scenarios also demonstrate external content, such as web pages relevant to the situation.

Avatar-driven scenarios use non-player characters (NPCs) in two forms: as 'chat bots', where the student interacts with the NPC to gather necessary information, or as avatars featured in Machinima (3D videos filmed within a virtual environment) such as a pre-recorded discussion, play or critical incident.

The role of the students, as a collaborative exercise, is to gather as much information about the situation and the disease as possible using a variety of information-driven methods before moving on to an avatar-driven method. The students are required to interact with a 'chat bot' to distinguish what their next actions should be.

\section{Methods}

The evaluation approach adopted was designed to increase understanding of what is being evaluated and focuses on the explorations of a learning situation. ${ }^{18}$ This approach was designed by Parlett and Hamilton ${ }^{19}$ originally due to concerns about the use of traditional approaches to evaluation which were being used to examine innovations in education. The aims of illuminative evaluation were:
"... to study the innovatory programme: how it operates; how it is influenced by the various school situations in which it is applied; what those most directly concerned regard as its advantages and disadvantages; and how students' intellectual tasks and academic experiences are most affected. It aims to discover and document what it is like to be participating in the scheme, whether as teacher or pupil; and, in addition, to discern and discuss the innovation's most significant features, recurring concomitants and critical processes. In short it seeks to illuminate a complex array of questions..."19

This move was away from psychology-based models of evaluation towards ones that were based in sociology.

The idea is that the evaluation is conducted through stages of evaluation that include observation, inquiry and explanations. Therefore data collection involved:

- Observation by an evaluator whose role was to collect and collate data. He observed a number of events such as meetings, social events and seminars and sessions in the virtual world

- Interviewing staff and students to explore and examine the interviewee's perceptions from a clearly personal and storied perspective

The evaluation encompassed formative elements to inform the project team and summative elements to establish the worth of what was achieved. The objectives of the evaluation were to:

- Explore the impact of problem-based learning scenarios in $3 \mathrm{D}$ virtual worlds on learning by observing sessions, interviewing staff and students and undertaking focus groups

- Assess the usability of the learning environments and user acceptance analysing students' perspectives and the use of the scenarios by the students both within and outside classroom hours

- Evaluate the effectiveness of feedback mechanisms and guidance materials through interviews and focus groups

- Offer an analytic account of the experience of the project from the perspective of all the key stakeholders through feedback at meetings, creating an interactive feedback cycle to ensure best practice

- Be responsive and flexible enough to capture unintended outcomes and unanticipated effects

- Provide an overall summary of the project, highlighting strengths, weaknesses and areas of development

- Inform current and future developments, paying particular attention to their structures, procedures, working practices, relationships and practices through publications and conference presentations 


\section{Data Collection}

Data were collected and analysed from three main sources: internal and external project documentation; interviews with key respondents (project leader, subject matter experts who designed and facilitated scenarios, learning technologists and the technical developer) and finally evaluation activities involving students.

In practice an iterative process was used when implementing and evaluating the PBL scenarios. At several stages throughout the project, testing of each scenario was undertaken, and the feedback from the students' experiences was analysed to improve on the scenarios. In practice testing took place over a period of 9 months using the two categories of PBL scenarios (avatar driven and information driven). Student evaluation data was collected from activities known as 'Testing days'. The paramedic scenarios were evaluated on three occasions during June and November 2008. In June participants who trailed the scenarios were first year paramedic students $(n=10)$ familiar with PBL and the university virtual learning environment, Blackboard, but not SL. The first retesting, which was carried out in a computer lab over 3 days in November involved four of the original ten participants and one new student. A further test in November used a different opportunity sample of ten mixed first and second year paramedic students. The structure of tests consisted of SL orientation (1hr), demonstration scenario (1hr) followed by group rotation around different scenarios (approximately $1 \mathrm{hr}$ per scenario). This was followed by a paper questionnaire and focus group (1hr). Scenarios were facilitated with groups of 2-4 students. The health care management scenarios were tested on two occasions with 12 different volunteers drawn from healthrelated professions, (not students on the target course) and almost all had no experience of PBL. None had prior experience of SL. These activities generated considerable volumes of data comprising in-world chat logs, video screen capture; video footage of the students interacting with scenarios, post testing focus group responses (videorecorded) and questionnaires.

Data were analysed interpretively to examine the subtext of data and identify themes and patterns of response in relation to the areas of enquiry. Findings were transformed into developmental models and practice materials.

At several stages throughout the project, testing of each scenario was undertaken, and the feedback from the students' experiences was analysed to improve on the scenarios. The scenarios were then reviewed further alongside students to ensure the feedback had been beneficial to the project.

\section{Ethical considerations}

Ethical clearance was gained through Coventry University Ethics committee and the principles of research governance were adhered to in terms of:

- the negotiation and interpretation of the data to ensure that the rights and opinions of those involved in the study were respected

- the provision of an information sheet giving details of the research, the researcher and the implications for all participants

- participants being informed fully about the purpose, methods and intended possible uses of the research, what their participation in the research entails, and what risks, if any, were involved

- the confidentiality of information supplied by research subjects and the anonymity of respondents was be respected

- the research participants' involvement will be seen as participating in a voluntary way, free from coercion

- avoidance of harm to research participants

- ensuring adherence to Coventry University procedures for research misconduct, complaints or appeals

- conflicts of interest being made explicit

- quality being assured through researcher reflexivity and trustworthiness

- research participants being informed about any possible risks

\section{Results}

The themes that emerged from the data were technological challenges, pedagogical design, usability and avatar identity, collaboration and interaction. The evaluation used a process of comparison between different data forms in order to present data that represented the overarching views of all these involved in the study.

\section{Technological challenges}

Feedback suggested that the information-driven scenarios did not work as well as avatar-driven, and the scenarios were restructured slightly to compensate for the students' comments that they did not feel as immersed into the environment with information-driven scenarios. The decision was made to design all the health care scenarios as avatar-driven to provide for a truly immersive and realistic experience.

It was anticipated that the technological demands and initial lack of user friendliness of SL would be a barrier to participation. Therefore as a precaution, for distance learners who may not have had the technical capabilities to run SL, a 'web application' was developed. In fact the technology also had a strong influence on the pedagogical model, as explained by two tutors:

"Second life lends itself to individuals or pairs consolidation or decision making exercise... like to see it as a standalone exercise without facilitation." 
"I don't feel it lends itself very well to a group (3-4)...- quite high boredom factor for those not directly participating with NPC, ... they were checking email, adjusting appearance so from facilitators point of view it is a good decision making exercise but not for what we understand as traditional PBL session."

Thus the outcomes were not particular PBL learning issues that students often identified, such as poor group work or a team member not contributing significantly.

\section{Pedagogical design}

When the PREVIEW project underwent testing by staff and students, few access barriers were reported, although this may become more of an issue with wider implementation of this approach. However, students who were beginners to the SL environment needed more time than anticipated to explore and experiment with the virtual world, and familiarise themselves with the new environment; mock scenarios became an important strategy in this process.

"This is my greatest concern. In order to get the students close to a point where clinical reasoning / learning is both valuable and the prominent area of concern. It seems to take a large amount of effort to overcome the heavy interface of second life."

"Second life lends itself very strongly to creating a rich and valuable decision making exercise."

This suggests that a degree of initial strangeness and discomfort may have been experienced by the participants, which is significant when considering that they would need a tolerable degree of conformity with the visual/kinetic /semiotic resources of the world and their avatar identity, before they could devote meaningful attention to group collaboration around a problem. One of the difficulties with using problem-based learning, designing interaction learning in virtual worlds and developing simulations is the ability to design and build effective complex and challenging scenarios. There is a tendency to focus on knowledge and content coverage, rather than the way learning will be managed and the complexity of the problem scenarios.

Schmidt and Moust ${ }^{20}$ suggested a taxonomy for using problems in order to acquire different kinds of knowledge, rather than solving problems or covering subject matter. The importance of the work undertaken by Schmidt and Moust is not only the way they provide and explicate different problem types, but also their exploration of the way in which the questions asked of students guide the types of knowledge in which students engage, as demonstrated in Table 1.

\section{Usability and avatar identity}

Designing learning in higher education has often focused on covering content and ensuring that discipline-based pedagogies are adhered to. What these data appear to indicate is that the experience of learning with and through Int J Med Educ. 2011; 2:116-124 an avatar differs between people, and invariably relates to identity transitions and transformations in immersive virtual worlds. Students remarked:

"I got distracted when my avatar was sitting on the cupboard instead of what I wanted 'her' to do."

"It does distract you when your avatar gets in the way. Just as I wanted to pick up information she started flying and I got confused and it interrupted the experience since I had to deal with the tech."

"I have to say that I wasn't really paying a tremendous amount of attention to my avatar in the actual scenario. I sat her down and then angled the camera so I couldn't even see her. I think I was in role - I tried to think like someone in that situation. I was just thinking like that as 'me', not as my avatar."

The sense of doing things differently, playing with learning, playing around and exploring were all seen as advantages to problem-based learning in SL. Yet these advantages were often seen by staff as troublesome in the sense that the learning boundaries were not necessary controlled and managed by them, but by the students. Yet for students it was the opportunity to play, which challenged the immutability of knowledge and the perception that learning was static and tutor centred. Yet such liquidity in the learning also brought with it a sense of unease about the provisionality of learning and identity in such spaces.

\section{Collaboration and interaction}

Preliminary results from the project indicate that SL held a great deal of potential for the development and extension of PBL. Students seemed able to use their avatars to communicate, collaborate and problem solve effectively.

"I liked it! It's more entertaining certainly! More fun. But I'm not sure that we'd have gotten different results if we sat around a table with a bunch of papers chatting."

"I liked the team collaboration aspect to it...I think it's a different way of working out solutions to problems. I liked it and it was fun!"

The level of realism and immersion of the scenarios seemed to be enhanced by the virtual world environment, including the option to use voice in addition to text-based communication, and students reported that it felt like a more 'authentic' learning environment than PBL based in VLEs. Students responded enthusiastically to the environment, interestingly tending to initially treat it as a 'game'. This (common) association of the look and feel of SL with online gaming may arguably be a limitation in the educational setting - in that it could encourage individualism rather than collaboration, and may simplify scenarios in which more nuanced critical engagement is required and no one clear solution is available. However, it is likely to also be an advantage in that it may increase student enjoyment and motivation via memorably novel forms of participation. 


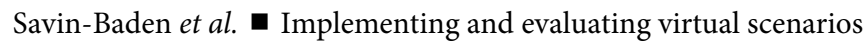

Table 1. Types of knowledge and types of problems

\begin{tabular}{|c|c|c|c|c|}
\hline Types of knowledge & Explanatory knowledge & Descriptive knowledge & Procedural knowledge & Personal Knowledge \\
\hline Types of problems & Explanation problem & Fact-finding problem & Strategy problem & Moral dilemma problem \\
\hline Examples & $\begin{array}{l}\text { People in the } 15^{\text {th }} \text { century } \\
\text { used to believe it was } \\
\text { possible to fall off the edge of } \\
\text { the earth }\end{array}$ & $\begin{array}{l}\text { Following recent political } \\
\text { changes relating to land use } \\
\text { in Zimbabwe many internal } \\
\text { borders have changed }\end{array}$ & $\begin{array}{l}\text { A } 43 \text { year old woman cannot lift } \\
\text { her right arm more than } 45 \\
\text { degrees and she complains of } \\
\text { pins and needles in her hand }\end{array}$ & $\begin{array}{l}\text { A mother breaks into a chemist's } \\
\text { shop at night to obtain lifesaving } \\
\text { drugs for her baby. She contacts } \\
\text { her local physician the next day to } \\
\text { explain what she has done }\end{array}$ \\
\hline Example of question & Explain why? & $\begin{array}{l}\text { What would a legal map look } \\
\text { like? }\end{array}$ & $\begin{array}{l}\text { If you were this client's } \\
\text { physiotherapist what would you } \\
\text { do? }\end{array}$ & What should the doctor do? \\
\hline
\end{tabular}

Reprinted with permission from McGraw-Hill. Savin-Baden M, Major C. Foundations of problem-based learning. Maidenhead: Open University Press/SRHE; 2004 , P. 67.

\section{Discussion}

New learning spaces and emerging technologies such as wikis and podcasts offer new possibilities in terms of communication in distance learning, but also present limitations and barriers in terms of the presentation of the self, meaningful synchronous interaction, and teambuilding. For these reasons, caution must be exercised when making claims for their equivalence to the communicative modalities of the face-to-face setting. When seeking to implement PBLonline, purpose-built educational virtual learning environments (VLEs) such as Blackboard may also be limited and limiting. These digital spaces (VLEs) have prompted concerns about both containment and exteriorisation in online environments. ${ }^{21}$ Containment is particularly evident in VLEs, inherent in their structuring and management of learning. Whilst many learning technologists ${ }^{22}$ have sought to account for academics' reported difficulties with using VLEs by citing lack of expertise or innovation, academics may in fact feel inhibited by a sense that the technology constrains rather than enables pedagogy, leading to a situation in which creativity is limited by a misguided quest for linearity and maintenance of control, prompted by the structuring force of the environment itself. Lyotard highlights the power-freighted and restrictive potential of the digital environment when he points out that

\footnotetext{
". . knowledge and power are simply two sides of the same questions: who decides what knowledge is, and who knows what needs to be decided? In the computer age, the question of knowledge is now more than ever a question of government". ${ }^{23}$
}

This project sought to implement and evaluate the problembased scenario in SL in a way that was pedagogically informed. It also developed an innovative approach to address problems faced by courses which wish to use problem-based learning as a tool for particular diagnostic skills such as problem-solving and decision making but are restricted in their opportunities for face to face learning. The approach took advantage of the new opportunities offered by immer- sive virtual worlds which provide the authenticity of a simulated real-world environment, and the open-ended nature of in-world activity. This may not be the first time that an attempt has been made to develop immersive scenarios, however we believe this may be the first use of PBL in immersive worlds in this way. Furthermore we believe this work builds on the taxonomy suggested by Schmidt and Moust. $^{20}$ A particular strength of SL as a learning environment is that it provides an interactive virtual space which is qualitatively different from discussion forums which is particularly important for PBL. This is because when using problem-based learning in virtual learning environments the discussion forums result in a linearity in learning which is unhelpful for team work. Using problem-based learning in SL student experience suggests both in this study and other related PREVIEW studies $^{3-7}$, that students value in-world interactive collaboration.

This study also indicates that students respond to welldesigned pedagogically driven scenarios that have been specifically designed for virtual world learning. Using PBL in SL embraces issues (such as student diversity and improving student engagement ${ }^{24}$ ) connected with complex curriculum design and the need for complex PBL scenarios to be developed. All the planned scenarios were delivered, and significant changes were made during development to take most advantage of SL's strengths. Students appreciated the value of SL as a collaborative environment, but also viewed such practice-based simulations as valuable for individual work. An interesting consequence of the richness and authenticity of the SL scenarios is the large amount of detail provided, much more than is usual in paper-based face-to face PBL sessions. SL can provide a more authentic learner environment than classroom based PBL and therefore changes the dynamic of facilitation, but at this stage it is not clear how this affects the way the scenario is used and facilitated. It has been pointed out that facilitation of PBL is itself a source of concern for many teachers ${ }^{25}$ and that there 
are differences and tensions to be resolved between online and face to face facilitation.

However, there were also technical considerations such as the relatively high specification computers/high bandwidths required, and the interface is not as intuitive as might be hoped. Interface complexity can provide memory overload. Furthermore, it is essential to prepare users through structured, context-related orientation sessions prior to use as a learning tool. Yet the user-guided development process adopted by PREVIEW, involving the whole multi-disciplinary development team and students from the target course worked effectively in highlighting strengths and weaknesses in many aspects of the scenarios.

Given the success of PREVIEW as a demonstrator, it is essential to build on these results to promote the embedding of effective scenarios when using problem-based learning in immersive virtual worlds in terms of the factors presented in Table 2.

Table 2. Factors to ensure PBL scenarios are embedded in virtual worlds

- Further development and research to develop models and understanding of good practice in areas such as scenario design in SL/MUVEs

- Exploration of technology reuse and repurposing

- Locating mechanisms to improve usability

- The development of PBL facilitation practices for SL/MUVEs

- Key issues for effective PBL

- What it means to learn in $\mathrm{SL}^{26,2 \prime}$

- Student preparation

- Usability and access issues

- Collaboration and interaction

Individual and collective identity work ${ }^{2}$

- Pedagogical design

Authenticity of the environment

Facilitation $^{28}$

What are students learning ${ }^{12}$

\section{Conclusions}

This project has a user-centred approach and has outlined a pedagogical approach to incorporating problem-based learning and virtual worlds in higher education. Developing open source pedagogically driven PBL scenarios such as these may offer a new liquidity to learning, combining technology with pedagogy in ways that are mutually beneficial not only in distance education, but also as a means to enrich the face-to-face learning environment. However, these environments must be examined not only in terms of the new freedoms they may afford, but also in recognition of their intermittently strange and 'troubling' nature, which may in itself provide potential for creativity. ${ }^{29}$ Such a vision however, will require that we stop seeing the curriculum as a predictable, ordered and manageable space, but instead review it as an important site of transformation characterised by risk and uncertainty.

\section{Conflict of Interest}

The authors declare that they have no conflict of interest.

\section{References}

1. Savin-Baden M. From cognitive capability to social reform? Shifting perceptions of learning in immersive virtual worlds. Association for Learning Technology Journal. 2008;16(3):151-61.

2. Warburton S. Second life in higher education: assessing the potential for and the barriers to deploying virtual worlds in learning and teaching. British Journal of Educational Technology. 2009;40(3):414-26.

3. Conradi E, Kavia S, Burden D, Rice A, Woodham L, Beaumont $\mathrm{C}$, et al. Virtual patients in a virtual world: training paramedic students for practice. Medical Teacher. 2009;31(8):713-20.

4. Poulton T, Conradi E, Kavia S, Round J, Hilton S. The replacement of 'paper' cases by interactive online virtual patients in problem-based learning. Medical Teacher. 2009;31(8):752-8.

5. Round J, Conradi E, Poulton T. Improving assessment with virtual patients. Medical Teacher. 2009;31(8):759-63.

6. Round J, Conradi E, Poulton T. Training staff to create simple interactive virtual patients: the impact on a medical and healthcare institution. Medical Teacher. 2009;31(8): 764-9.

7. Beaumont C, Savin-Baden M, Conradi E, Poulton T. Evaluating a second life PBL demonstrator project: what can we learn? Interactive Learning Environments. 2011;20(1):5-21.

8. Barrows HS, Tamblyn RM. Problem-based learning: an approach to medical education. New York: Springer; 1980.

9. Ebenezer C. User survey conducted at the medical library of the University of Limburg at Maastricht. 1993 [cited 2011 September 15]; Available from: http://hdl. handle.net/10150/105336.

10. Savin-Baden M. Problem-based learning in higher education: untold stories. Buckingham: Open University Press; 2000.

11. Savin-Baden M. A practical guide to problem-based learning Online. London: Routledge; 2007.

12. Savin-Baden M. A practical guide to using second life in higher education. Maidenhead: McGraw-Hill; 2011.

13. Savin-Baden M, Major C. Foundations of problembased learning. Maidenhead: Open University Press; 2004.

14. Ravenscroft A, Matheson MP. Developing and evaluating dialogue games for collaborative e-learning. Journal of Computer Assisted Learning. 2002;18(1):93-101.

15. Dede C. Planning for neomillennial learning styles: implications for investments in technology and faculty. In: Oblinger DG, Oblinger JL, editors. Educating the net generation. Boulder, CO: Educause; 2005.

16. Sharpe R, Beetham H, de Freitas S. Rethinking learning for a digital age: how learners are shaping their own experiences. London: Routledge; 2010. 
17. Savin-Baden M, Beaumont C, Poulton T, Conradi E. Students' experiences of learning in immersive world environments. Open University2008 [updated 22-23 November; cited 2011 July 19]; Available from: http://www.open.ac.uk/relive08/catch-up.shtml.

18. Parlett M, Dearden G. Introduction to illuminative evaluation: studies in higher education. California: Pacific Soundings Press; 1977.

19. Parlett M, Hamilton D. Evaluation as illumination: a new approach to the study of innovatory programs. Edinburgh: Centre for Research in the Educational Sciences, University of Edinburgh; 1972.

20. Schmidt HG, Moust JHC. Towards a taxonomy of problems used in problem-based learning curricula. Journal on Excellence in College Teaching. 2000;11(2/3):57-72.

21. Land R. Paradigms lost: academic practice and exteriorising technologies. E-Learning and Digital Media. 2006;3(1):100-10.

22. Beetham H, Sharpe R. Rethinking pedagogy for the digital age: designing and delivering e-learning. London: Routledge; 2007.

23. Lyotard J. The postmodern condition: A report on knowledge. Manchester: Manchester University Press; 1979.
24. Wimpenny K, Savin-Baden M. Alienation, agency and authenticity: a synthesis of practice and effects in student engagement. Teaching in Higher Education., in press.

25. Savin-Baden M, Wilkie K. Introduction. In: SavinBaden M, Wilkie K, editors. Problem-based learning online. Maidenhead: Open University Press; 2006.

26. Minocha S, Reeves A. Interaction design and usability of learning spaces in 3D multi-user virtual worlds. In: Katre D, Orngreen R, Yammiyavar P, Clemmensen T, editors. Human Work Interaction Design: Usability in Social, Cultural and Organizational Contexts. New York: Springer; 2010.

27. Kemp JW, Haycock K. Immersive learning environments in parallel universes: learning through second life. School Libraries Worldwide. 2008;14(2):89-97.

28. Savin-Baden M. The challenge of using problem-based learning online. In: Savin-Baden M, Wilkie K, editors. Problem-Based Learning Online. Maidenhead: McGrawHill; 2006.

29. Bayne S. Temptation, trash and trust: the authorship and authority of digital texts. E-Learning and Digital Media. 2006;3(1):16-26.

\section{Appendix 1: Examples}

\section{PBL Scenario in Second Life for Health and Social Care Management}

Scenario You each represent a part of the management of an NHS residential / nursing care service - The Cedars Care Complex. There is community concern about Clostridium difficile infection and your own Service is experiencing higher rates of deaths than the average. A front page newspaper article published today is not helping matters.

Explanation The students arrive in world at the Cedars Care Complex. In the office area there is a ringing phone, which when answered, is a message from the local councillor who says he will be along shortly to discuss the C. diff crisis. There is information in the room such as web links and the newspaper article. When the students are ready, they can press a button on the table to call the councillor who subsequently arrives within a few seconds. The students then interact with the councillor (a chatbot) and discuss his concerns. When the interaction is finished the councillor is scripted to disappear and instructs them to create a plan for what to do next. At this point the students must work on a plan together for the Care Complex's next course of action.

2. Activity for students on an undergraduate Nursing or Paramedic programme (supplied by Kerry Cook, Coventry University)

Aim of the session The session aims to enable students to manage compound and simple fractures in both upper and lower limbs, and will support the participant with all the basic and background information which will facilitate the management process.

Learning intentions On successful completion of the session the students will be able to demonstrate achievement of the following learning outcomes:

1. Describe the structure and function of the skin, upper and lower limbs.

2. Differentiate between compound and simple fractures.

3. Examine a patient with compound and simple fractures.

4. Manage difficult circumstances.

5. Treat a patient with compound and simple fractures.

6. Communicate with the relevant personnel to plan for patient hospitalisation.

Case scenario Alex is a 30 year old male working as a car designer / painter, married with 2 children. He prefers to use his motorcycle rather than his car as it is faster and more manoeuvrable in traffic, since he is usually travelling to and from work during the rush hour. One day he had an appointment with a new client and particularly wanted to be punctual, as there was the chance that the client would bring in a lot of extra business. At 8.30 am on a very busy road he was in collision with a truck, whose driver was trying to avoid a car and did not see Alex alongside him on his motorcycle. Alex was thrown from the motorcycle and landed on the road. Inevitably the accident caused disruption to the traffic and the area became severely congested.

Actions Your station received an emergency call reporting the accident and the place where it occurred. The operation room directed the crew to the site of the accident and you were informed that the area was congested and the traffic static. You are the leader of the crew.

1. What is your plan of action?

2. On arrival at the scene, what is your plan of action?

NB: from your first observation of Alex, his left arm is injured and bleeding, he is conscious but in severe pain 